\title{
ANALISIS FORMULASI MUTU HOTMIX KONVENSIONAL DAN HOTMIX RECYCLING PADA JALAN TOL IR. WIYOTO WIYONO
}

\author{
Yogi Oktopianto ${ }^{1}$, M Fathullah ${ }^{2}$ \\ ${ }^{1}$ Program Studi Manajemen Keselamatan Transportasi Jalan \\ 2PT. Citra Marga Nusaphala Persada, Tbk \\ Politeknik Keselamatan Transportasi Jalan \\ Jalan Semeru No.3 Kota Tegal, Jawa Tengah 52125 \\ E-mail: yogi.oktopianto@pktj.ac.id
}

\begin{abstract}
Abstrak
Program penggantian aspal merupakan program rutin pada pemeliharaan jalan tol untuk memenuhi Standar Pelayanan Minimum. Keterbatasan biaya pemeliharaan, beban kendaraan yang masih susah untuk dikendalikan, Pengaruh iklim tropis yang mempercepat kerusakan perkerasan jalan dapat memberi dampak terhadap rendahnya kinerja perkerasan jalan menjadi dasar penelitian ini serta hasil kupasan lapis permukaan beraspal yang biasa disebut Reclaimed Asphalt Pavement (RAP) belum termanfaatkan dengan baik. Hotmix Recycling merupakan suatu teknik daur ulang yang dapat diterapkan pada rehabilitasi dan pemeliharaan perkerasan jalan. Penelitian dilakukan untuk mengetahui formulasi kualitas hotmix konvensional dan hotmix recycling. Metode yang digunakan dalam penelitian ini adalah eksperimental dengan melakukan pengujian laboratorium terhadap material aspal bekas. Hasil penelitian didapatkan bahwa kualitas antara hotmix recycling dan hotmix konvensional hampir sama. Formulasi RAP dan fresh material optimal yang didapatkan 30:70 dengan parameter stability hotmix recycling lebih tinggi dibandingkan hotmix konvensional bertur-turut 1677,98 $\mathrm{kg}$ dan $1600 \mathrm{~kg}$ dengan standar minimum sebesar $1100 \mathrm{~kg}$.
\end{abstract}

Kata kunci: Hotmix recycling, aspal daur ulang, reclaimed asphalt pavement, RAP

\section{PENDAHULUAN}

Pembangunan, rehabilitasi, dan pemeliharaan jalan memiliki beberapa persoalan mendasar. Misalnya adanya keterbatasan biaya pembangunan dan pemeliharaan, beban kendaraan yang masih susah untuk dikendalikan, Pengaruh iklim tropis yang mempercepat kerusakan perkerasan jalan, dan hal-hal lain yang dapat memberi dampak terhadap rendahnya kinerja perkerasan jalan. Ruas jalan Tol Ir. Wiyoto Wiyono menggunakan teknologi perkerasan lentur atau perkerasan beraspal, yaitu lebih dari $90 \%$ dari seluruh panjang jalan yang ada. Meningkatnya penggunaan material aspal secara pereodik dalam pemeliharaan menyebabkan kurangnya ketersediaan material dan sudah mulai habis keberadaannya sebagai sumber daya alam yang tidak dapat diperbaharui. Serta hasil kupasan lapis permukaan beraspal yang biasa disebut Reclaimed Asphalt Pavement ( $R A P$ ) belum termanfaatkan dengan baik, bahkan bisa menyebabkan masalah-masalah lain. Alternatif untuk mengatasi kendala kekurangan aspal adalah pemanfaatan RAP, khususnya untuk pekerjaan pemeliharaan (perbaikan atau rekonstruksi) jalan dengan menggunakan metode cut and fill. Metoda ini merupakan green technology karena memanfaatkan limbah dari perkerasan jalan. Pemanfaatan RAP ini dapat mengurangi penggunaan aspal baru sehingga dapat mengefisienkan pemakaian produk. Tujuan dari penelitian ini untuk 
mengetahui formulasi kualitas hotmix konvensional dan hotmix recycling.

\section{METODE PENELITIAN}

Jenis penelitian ini adalah eksperimental dengan melakukan pengujian laboratorium terhadap material aspal. Stok Material RAP mentah yang digunakan berasal dari lokasi Tol milik PT. Citra Marga Nusaphala Persada, Tbk, yang selanjutnya dilakukan observasi terhadap nilai-nilai karakteristik bahan di laboratorium. Tahapan dalam proses Hotmix Recycling mulai dari proses pengujian karakteristik RAP, variasi kombinasi fresh material dan RAP, hingga proses pengegelaran hotmix di lapangan.

\section{HASIL DAN PEMBAHASAN}

\section{A. RECLAIMED ASPHALT PAVEMENT (RAP)}

\section{Stok Material RAP Mentah}

Stok Material RAP mentah yang digunakan berasal dari hasil scrapping eksisting. Material RAP tersebut selanjutnya di lakukan pemecahan atau penguraian material RAP antara material halus dan kasar menggunakan alat Granulator

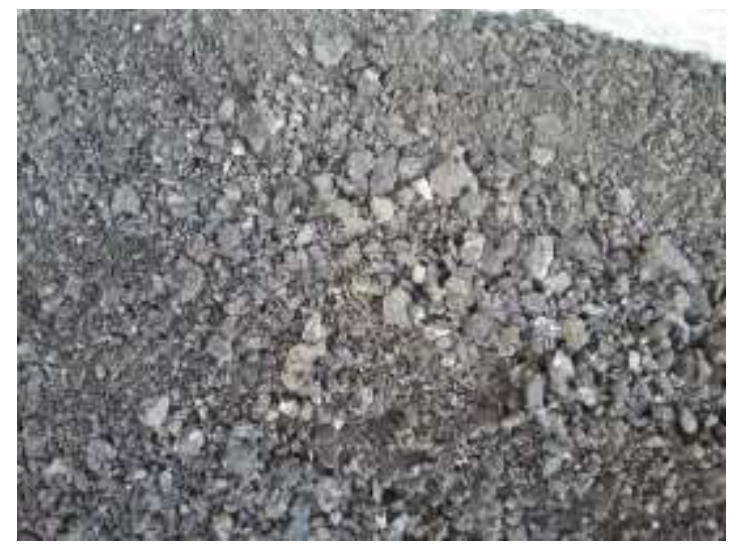

Gambar.1 Kondisi Fisik RAP

\section{Pemecahan material RAP dengan Alat Granulator}

Alat Granulator merupakan alat yang digunakan untuk menguraikan material RAP. Material RAP mentah yang sudah terkumpul pada storage RAP selanjutnya dikeruk menggunakan Wheel Loader kemudian di tuang ke Granulator. Setelah terjadi proses penguraian material kasar dan halus selanjutnya material akan turun atau keluar ke ban conveyor menuju penyaringan yang ada di ujung conveyor.

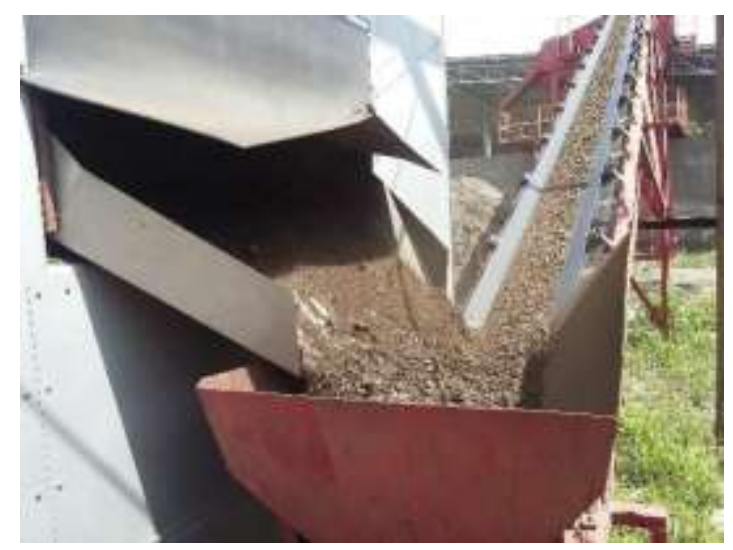

Gambar.2 Pemecahan material RAP 


\section{Sampling Material RAP}

Sampling material RAP dilakukan dengan mengambil sampel dari bagian bawah, tengah dan puncak tumpukan material RAP hasil granulator. Per bagian tersebut material RAP diambil 3-5 kg.

\section{Ekstraksi Material RAP}

RAP yang didapatkan dari hasil sampling selanjutnya di ekstraksi. Ekstraksi dimaksudkan untuk memisahkan antara agregate dan bitumen yang ada pada material RAP dengan menambahkan pelarut yang dapat malarutkan salah satu bahan.

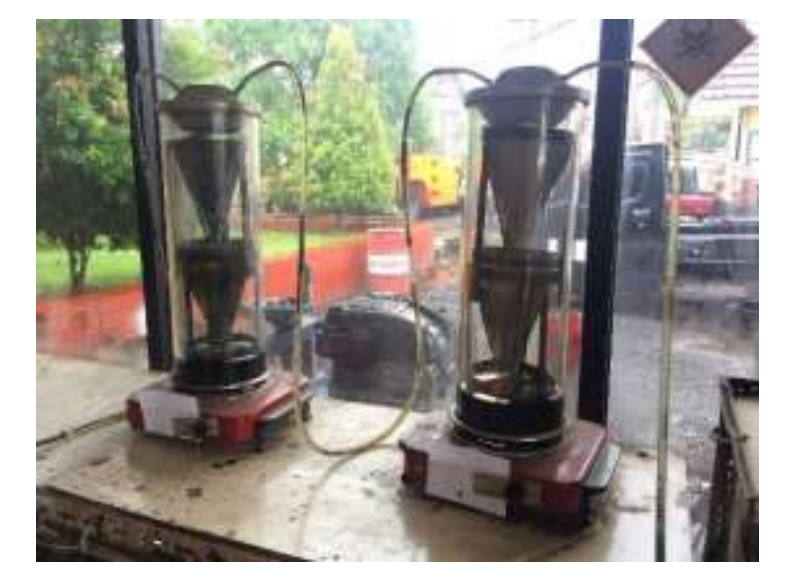

Gambar.3 Pengujian Ekstraksi Material RAP

\section{Gradasi Agregate Ex-RAP}

Agregate Ex-RAP dihasilkan dari proses ekstraksi. Agregate Ex-RAP selanjutnya di gradasi dengan tujuan untuk mengetahui distribusi besaran atau jumlah persentase butiran baik aggregate halus dan agregate kasar.

\section{Bitumen Ex-RAP}

Bitumen Ex-RAP yang dihasilkan dari hasil ekstraksi masih bercampur dengan bahan kimia TCE. Untuk memisahkan antara Bitumen murni Ex-RAP dengan TCE perlu dilakukan tes abson melalui penyulingan.

\section{Tes Abson Bitumen Ex-RAP}

Tes abson bitumen Ex-RAP mengacu pda SNI 2490:2008 tentang cara uji kadar air dalam produk minyak dan bahan mengandung bitumen dengan cara penyulingan.

\section{Pengujian Variasi fresh aspal + aspal RAP}

Tes abson memisahkan antara bitumen murni Ex-RAP dengan bahan pelarut TCE. Selanjutnya dilakukan pengujian properties dengan beberapa variasi fresh bitumen dengan bitumen murni ex-RAP. Tujuan dilakukannya pengujian variasi ini adalah untuk mendapatkan variasi yang terbaik yang memenuhi spesifikasi bitumen keras penetrasi 60/70. Adapun variasi fresh bitumen dan bitumen murni ex-RAP sebagai berikut:

1. Bitumen murni Ex-RAP

2. Bitumen Murni Ex-RAP + Additive interlene 4\%

3. Bitumen Murni Ex-RAP 30\% + Bitumen Fresh $70 \%$

4. Bitumen Murni Ex-RAP 30\% + Bitumen Fresh 70\% + Additive interlene 4\%

5. Bitumen Murni Ex-RAP 20\% + Bitumen Fresh $80 \%$

6. Bitumen Murni Ex-RAP 20\% + Bitumen Fresh 80\% + Additive interlene 4\% Parameter yang diuji dari masing masing variasi diatas adalah Penetrasi, titik lembek dan daktilitas. 
Tabel 1. Hasil Uji Penetrasi, Titik Lembek dan Daktilitas variasi bitumen murni dan RAP

\begin{tabular}{|c|c|c|c|c|c|}
\hline No & Item variasi & Penetrasi & Titik Lembek & Daktilitas & Keterangan \\
\hline 1 & Bitumen Ex-RAP & 16,33 & 76,68 & 9,5 & NOT OK \\
\hline 2 & $\begin{array}{l}\text { Bitumen Ex-RAP +Additiv } \\
\text { Iterlene } 4 \%\end{array}$ & 29,13 & 64,75 & 23,75 & NOT OK \\
\hline 3 & $\begin{array}{l}\text { Bitumen Ex-RAP 30\% + } \\
\text { Bitumen Fresh } 70 \%\end{array}$ & 51,55 & 57,94 & 125,5 & NOT OK \\
\hline 4 & $\begin{array}{l}\text { Bitumen Ex-RAP } 30 \% \\
\text { + Bitumen Fresh } 70 \% \\
\text { + Additive iterlene } 4 \%\end{array}$ & 60,80 & 55,75 & 135 & OK \\
\hline 5 & $\begin{array}{l}\text { Bitumen Ex-RAP } 20 \%+ \\
\text { Bitumen Fresh } 80 \% \\
\text { Bitumen Ex-RAP } \mathbf{2 0 \%}\end{array}$ & 55,15 & 56,75 & 137,5 & NOT OK \\
\hline 6 & $\begin{array}{l}\text { + Bitumen Fresh } 80 \% \\
+ \text { Additive iterlene } 4 \%\end{array}$ & 63,25 & 55,25 & $>140$ & OK \\
\hline Spe & ifikasi & $60-70$ & $48-58$ & $\geq 100$ & - \\
\hline
\end{tabular}

Berdasarkan hasil pengujian parameter diperoleh hasil bahwa variasi yang memenuhi spesifikasi parameter penetrasi, titik lembek, dan daktilitas adalah variasi

1. Bitumen Murni Ex-RAP 30\% + Bitumen Fresh 70\% + Additive interlene 4\%

2. Bitumen Murni Ex-RAP $20 \%$ + Bitumen Fresh $80 \%$ + Additive interlene $4 \%$

3. Adapun dengan pertimbangan biaya produksi, biaya operasional, serta besarnya RAP yang dapat di recycle maka variasi Bitumen Murni Ex-RAP 30\% + Bitumen Fresh $70 \%$ + Additive interlene $4 \%$ dapat dipilih sebagai kombinasi yang memenuhi aspek lingkungan, mutu, dan biaya.

\section{B. FRESH MATERIAL}

\section{Fresh Bitumen}

Fresh bitumen yang digunakan pada pencampuran hotmix recycling merupakan jenis bitumen shell pen 60/70.

\section{Fresh Agregate}

Agregat merupakan campuran dari pasar, kerikil, batu pecah atau material lain yang berasal dari bahan material alami atau buatan. Agregat merupakan komponen utama dari struktur perkerasan jalan, yaitu 90-95 \% agregat berdasarkan persentase berat.

\section{Jobmix Kombinasi Material ex-RAP, Fresh Agregate dan Fresh Bitumen}

Kegiatan percobaan terhadap campuran aspal panas (hotmix) dilakukan untuk mendapatkan suatu campuran yang memenuhi syarat dan spesifikasi. Kegiatan ini disebut dengan kegiatan jobmix. Kegiatan Jobmix diawali dengan menguji properties bitumen dan agregate, pembuatan design mix (analisa saringan, mengkombinasikan agregate yang berasal dari coldbin untuk dianalisis menggunakan metode grafis diagonal, dan memperkirakan kebutuhan bitumen), selanjutnya dilakukan pembuatan FCR (Formula campuran Rancangan), dan Trial mix serta Compaction di lapangan.

\section{Design Mix}

Campuran untuk hotmix terdiri dari agregat kasar, agregate halus, dan bitumen. Masing-masng agregate diperiksa gradasinya kemudian digabungkan menurut perbandingan yang akan menghasilkan agregate campuran yang memenuhi persyaratan. Setelah itu ditambahkan bitumen secukupnya pada campuran agregate hingga dihasilkan hotmix. 


\section{Pengujian FRC (Formula Campuran Rancangan)}

Pengujian FRC dimulai dari Analisa saringan aggregate di hotbin, kombinasi agregate yang berasal dari hotbin untuk dianalisis menggunakan metode grafis diagonal, Pengujian spesifik grafity dari agregate kasar, Spesific grafity dari agregate halus, pengujian film thickness, pengujian berat jenis campuran maksimum (GMM), Percobaan kepadatan membal Refusal, Percobaan marshall, dan Stabilitas marshall.

\section{Trial Compaction Laboratorium}

Kegiatan trial compaction di laboratorium meliputi kegiatan ektrasksi hotmix produksi yang diambil dari hotbin, gradasi hasil ekstraksi, pengecekan pembagian butir, dan bitumen film thickness. Selain kegiatan-kegiaan tersebut juga dilakukan monitoring quality harian produksi Hotmix Recycling.

\section{Pengujian Paper Test dan Core Drill di Lapangan}

Kegiatan di lapangan untuk menunjang kebutuhan di laboratorium diantaranya adalah monitoring tebal tack coat hasil penghamparan di lapangan dan pengambilan sampel core drill. Tack Coat yang digunakan pada proses penggelaran hotmix recycling adalah jenis CRS 1 PX. Jenis tack caot ini digunakan untuk melekatkan hotmix eksisting dengan hotmix baru yang memiliki keunggulan lebih rekat dan tidak mudah lepas dibandingkan CRS 1.

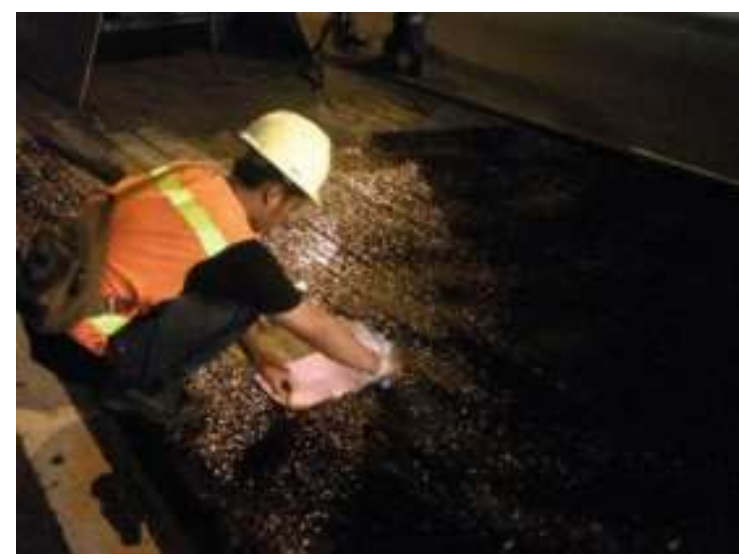

Gambar.4 Pengujian Paper Test

\section{Penggelaran Hotmix Recycling di Lapangan}

Penghamparan hotmix recycling dengan menggunakan alat asphalt Finisher. Sebelum hotmix dituangkan dari dump truck ke dalam asphalt finisher, suhu hotmix diukur dahulu dengan termometer pada beberapa colokan di atas dump truck untuk mewakili dan atas rekomendasi konsultan pengawas / pemilik proyek apakah layak atau tidak layak untuk digelar. Pada proses penggelaran dengan asphalt finisher pada lokasi yang sudah di coating, yang harus diperhatikan dalam pelaksanaannya diantaranya ketebalan gelaran, kecepatan asphalt finisher dalam menghampar harus diperhatikan supaya tidak terjadi retak permukaan, belahan atau ketidak teraturan permukaan, Hotmix tidak boleh mendingin / menggumpal pada sisi-sisi hopper atau kuping screed asphalt finisher.

\section{Hasil Perbandingan Kualitas Hotmix Recycling dengan Hotmix Konvensiona} Hasil perbandingan pengujian jobmix recycling dengan hotmix konvensional didapatkan hasil seperti pada Tabel 2 . Berdasarkan hasil pengujian didapatkan bahwa kualitas antara hotmix recycling dan hotmix konvensional hampir sama. Bahkan parameter seperti Stability hotmix recycling lebih tinggi dibandingkan hotmix konvensional. 
Tabel 2. Perbandingan Kualitas Hotmix Recycling dengan Hotmix Konvensiona

\begin{tabular}{|c|c|c|c|c|c|}
\hline No & Discription & $\begin{array}{c}\text { Hotmix } \\
\text { Konvensional }\end{array}$ & $\begin{array}{l}\text { Hotmix } \\
\text { Recycling }\end{array}$ & Spesifikasi * & Keterangan \\
\hline 1 & Penyerapan Asphalt & 0,805 & 0,809 & Maks. 1.2 & OK \\
\hline 2 & $\begin{array}{l}\text { Asphal Content } \\
\text { /Shell 60/70 }\end{array}$ & 5,9 & 6,22 & - & OK \\
\hline 3 & Density & 2284 & 2285 & - & OK \\
\hline 4 & Void Mineral Agregat & 17,00 & 17,01 & Min. 15 & OK \\
\hline 5 & Air Void & 4,12 & 4,08 & $3.0-5.0$ & OK \\
\hline 6 & $\begin{array}{l}\text { Void Filled With } \\
\text { Asphalt }\end{array}$ & 76,00 & 76,03 & Min. 65 & $\mathrm{OK}$ \\
\hline $\begin{array}{l}7 \\
8\end{array}$ & $\begin{array}{l}\text { Stability } \\
\text { Flow }\end{array}$ & $\begin{array}{c}1600 \\
3,84\end{array}$ & $\begin{array}{c}1677,98 \\
3,78\end{array}$ & $\begin{array}{l}\text { Min. 1,100 } \\
\text { Min. } 3\end{array}$ & $\begin{array}{l}\text { OK } \\
\text { OK }\end{array}$ \\
\hline 9 & $\begin{array}{l}\text { Marshall Qoutient } \\
\text { Stability Marshall }\end{array}$ & 425 & 443,36 & Min. 250 & OK \\
\hline 10 & $\begin{array}{ll}\text { setelah } & \text { rendam } 24 \\
\text { Jam, } & \text { Temperatur } \\
60^{\circ} \mathrm{C} & \end{array}$ & 90,849 & 91,777 & Min. 90 & OK \\
\hline 11 & $\begin{array}{l}\text { Bitumen } \\
\text { Thicness }\end{array}$ & 9,128 & 10,484 & - & OK \\
\hline 12 & Kadar Asphalt (\%) & 5,9 & 5,45 & Min. 4.3 & OK \\
\hline
\end{tabular}

Sumber: Hasil Pengujian Laboratorium, 2018

\section{PENUTUP}

\section{Simpulan}

Proporsi formulasi RAP dan fresh material optimal yang didapatkan dari hasil penelitian ini adalah 30:70. Nilai ini didapatkan melalui hasil tes aspal gabungan dari RAP dan fresh yang mengacu pada sifat penetrasi 60/70. Kualitas hotmix recycling dengan hotmix konvensional setara dimana jika dibandingkan menggunakan spesifikasi Bina Marga 2010 rev.3.

\section{Saran}

Perlu dilakukan penelitian lebih lanjut untuk mendapatkan proporsi maksimal antara RAP dan fresh material, dengan penggunakan jenis additive dan campuran lainya.

\section{DAFTAR PUSTAKA}

Balitbang (2012). Recycling (Teknologi Daur Ulang Perkerasan Jalan), litbang.pu.go.id/ recycling-teknologi-daur-ulang-perkerasan jalan

Lembaga Pengembangan Jasa Konstruksi (2013). Perkerasan Aspal Jalan Daur Ulang (Recycling), www.lpjk.org/modules/article.php

Rahman, H., dkk (2011). Kinerja Kelelahan Campuran Beton Aspal Lapis Aus Menggunakan Material Hasil Daur Ulang Dan Polimer Styrene-Butadiene-Styrene, Jurnal Transportasi Vol. 11 No. 3 Desember 2011 : 163-172.

Kasan, M., (2009). Studi Karakteristik Volumetrik Campuran Beton Aspal Daur Ulang, Jurnal SMARTek, Vol. 7, No. 3, Agustus 2009: 152 - 165.

Suroyo, H., (2004). Pengaruh Daur Ulang Bahan Bongkahan Aspal terhadap Sifat-sifat Beton Aspal (Studi Kasus di Jalan Gajahmada Tegal), Tesis Program Pasca Sarjana Universitas Diponegoro.

Spesifikasi Umum Bina Marga Divisi 6 (2010). Perkerasan Aspal, Direktorat Jenderal Bina Marga. 